\title{
LEAF COMPOSITION OF LOWLAND RICE AND SUGAR CANE AS AN INDICATOR OF THEIR PERFORMANCE
}

\author{
GO BAN HONG and J. VAN SCHUYLENBORGH $\left.{ }^{2}\right)^{3}$ )
}

\begin{abstract}
SUMMARY
Nutrient uptake studies were conducted with lowland rice and sugar cane as dependent on time. Foliar composition, characterized by the element-concentration ratios, was taken as an index of their nutritive state. It appeared that the ratios of the major elements remain fairly constant in the whole growing season and that these are indicative for crop yield and crop quality. It is therefore possible to analyse both crops in a very early stage of development; this is advantageous as no choice of which leaf has to be analysed is needed. The whole above ground part can be sampled without the danger of obtaining too voluminous a sample. The possibility of an early analysis allow to correct for an eventually inadequate nutritive state of the plant in the same growing season.

The mobilities of the major elements could be arranged in following order of decreasing mobility: $\mathrm{PO}_{4}>\mathrm{N}>\mathrm{K}$ for the rice plant, and $\mathrm{N}>\mathrm{PO}_{4} \geqslant \mathrm{~K}$ for the sugar cane plant.
\end{abstract}

\section{INTRODUCTION}

The composition of the leaf is generally taken as a measure for the nutritional status of the plant. This is understandable as the synthesis of organic substances (photosynthesis) is particularly taking place in the leaves.

The composition of the leaves, however, is very variable and depends on : the age of the leaves, the morphological position, climate (time of sampling), daytime, etc. (See a.o.: Goodall and Gregory, 1947 ; Broeshart, 1955). For the interpretation of leaf analyses, it is therefore necessary to sample leaves of the same morphological position at the same time of the year and the day and at the same age. This is very difficult and, therefore, leaves of the same physiological age are generally chosen, although the composition will not necessarily be the same as a consequence of the possible difference in dry matter content (a.o. Brofshart, 1955). Moreover, different parts of the leaves can differ in composition, so that a special part of the leaf should be sampled. This is particularly advisable if whole leaves cannot be gathered because of the resulting voluminosity of the sample.

As all these facts contribute to the uncertainty of the results of foliar analysis, it is advisable to investigate the question whether or not there is a relation between leaf composition at an early stage of development and final yield and/or quality of the crop. Foliar analysis at such an early stage has the advantage that all the leaves can be taken without the danger of too large a sample, thus avoiding the difficult choice as to which leaf or part of the leaf should be taken for the analysis.

With respect to the above mentioned suggestion it is of interest to remark that especially the ratio of the element-concentrations in the leaves is important for production rather than their absolute contents, if the elements are not in a minimum. This is especially true for quality crops, such as sugar cane,

1) The results of the rice experiments were part of the doctor's thesis of the senior author; University of Indionesia, Bogor.

2) Present address of the latter author: Edeseweg $100 \mathrm{I}$, Bennekom, The Netherlands.

3) Received for publication February 11, 1959. 
tobacco, oil palm, etc. (see e.g. Barty and Anderson, 1929; Mmbelburg, 1932, 1937 ; Beauchamp and Lazo, 1938; Broeshart, 1955; van Schuxlenborgh and SARJADI, 1958). So, if it appears that the ratio of the element-concentrations is constant after an early stage of development, it is possible to sample and to analyse the crop at that young age and to interprete the results. It is then also possible to correct an eventually inadequate ratio by suitable supply of fertilizers.

A method to investigate this problem is to grow a certain crop under good control (e.g. pot experiments under greenhouse conditions) and to sample the crop at regular, preferably short, time intervals and to analyse the different parts of the plants. This was done in detail for the lowland rice (see also: Go BAN HoNG, 1957) and in less detail for sugar cane.

\section{EXPERIMENTAL}

Rice (variety "Tjina") was grown in culture solutions and in soil obtained from the $A_{1}$-horizon of a "Reddish-Brown Latosol" near Bogor, Indonesia. The experiments were conducted from june to november 1956 (series I: preliminary series) and from november 1956 to may 1957 (series II and III). Series IV was the experiment with the culture solution. In each growing season a blank was run.

The soil was excessively moistened and thoroughly puddled. During this puddling part of the fertilizers was added to obtain an even distribution through the soil. Because it appeared that the fertilizer supply of series I was quite inadequate (indicated by the appearance of phosphate - and nitrogen - deficiency symptoms at a certain stage of development), the scheme was corrected in series II and III. For details it be referred to table 1. The culture solution of series IV was a slightly modified Hoagland-solution (HoAgland and Arnon, 1938); the composition is given in table 2 . The solutions were aerated daily and refreshed weekly.

The rice plants, used for the soil cultures, were first grown for 30 days on seedbeds, as is usage in practice, and then transplanted to the pots; in series I three plants and in series II and III two plants were used. The number of replications was 5 in series I and 4 in series II and III. The soil was left under a water-layer of $3 \mathrm{~cm}$ thickness. For the water-cultures the seeds were germinated on moist filter paper and transplanted after 5 days; one plant per jar was used. The age of the plants was taken from the time of transplantation.

The rice crop was harvested every 10 to 21 days; the plants were seperated in their constituent parts and immediately dried at $100^{\circ} \mathrm{C}$. After dryness the material was ground in a Peppink mill. The thus obtained samples were analysed with request to their $\mathrm{N}, \mathrm{PO}_{4}, \mathrm{~K}, \mathrm{Ca}, \mathrm{Mg}, \mathrm{Na}, \mathrm{Si}$ and $\mathrm{Fe}$-content. Only the results with the major-elements will be reported in this paper. As th? mass of the leaves is in abundance over those of stems and roots, so that the composition of the whole plant is very close to that of the leaves, only the analytical results with dead and green leaves will be given below.

The same soil was used for the sugar cane experiment. The sugar cane clone was POJ 3061. It was grown from July 1956 to June 1957. The number of replications was three. The "bibit" was placed at a depth of $15 \mathrm{~cm}$ below the surface. After 1 month they were covered with soil. The total supply of fertilizers was : $5 \mathrm{~g} \mathrm{~N}$ as ammonium sulphate; $1 \mathrm{~g} \mathrm{PO}_{4}$ as monocalciumphosphate; 
$10 \mathrm{~g} \mathrm{~K}$ as potassium sulphate; $0,8 \mathrm{~g} \mathrm{Mg}$ as magnesium sulphate; and $0,8 \mathrm{~g}$ $\mathrm{Ca}$ as calcium nitrate. One fourth of the fertilizers was mixed with the soil and one seventh of the remaining part was added monthly from the third month onward.

The cane plants were harvested monthly; leaves and stems for the analysis of $\mathrm{N}, \mathrm{PO}_{4}, \mathrm{~K}, \mathrm{Ca}, \mathrm{Mg}$, and $\mathrm{Na}$. (Only the results of the analyses of the major elements will be given here). Time of sampling was in the early morning within three hours after sunrise, as was advised by the Experiment Station, H.S.P.A. (1944).

Nitrogen was determined semi-microchemically according to Kjeldahl (see: Paech and Tracey, vol. I, 1956, p. 479). For the estimation of the other elements the plant material was digested with the acid mixture $\mathrm{H}_{2} \mathrm{SO}_{4}+\mathrm{HNO}_{3}$ $+\mathrm{HClO}_{4}$ according to WaLkLEY (1942). Phosphate was determined with the ScHEEL-method (1936), and potassium with the flame photometer of LANGE.

\section{Results}

The element-concentration ratios of the leaves of the rice plant are given in table 3. A surprising constancy of the ratios can be noted, especially in the water-cultures, although there is a tendency in the N/K-ratio to reach a minimum value at the age of 78 days. The same constancy can be stated in series II and III with the exception of the composition at 21 and 42 days, and of the composition at the stage of ripening. The $\mathrm{N} / \mathrm{PO}_{4}$-ratio shows high values at those ages, whereas the $\mathrm{N} / \mathrm{K}$-ratio remains fairly constant. The high values of $\mathrm{N} / \mathrm{PO}_{4}$ coincided with the appearance of phosphate-deficiency symptoms ; apparently the phosphate became increasingly unavailable because of the rising soil $\mathrm{pH}$ and it was decided to give an additional amount of phosphorus in the form of phosphoric acid (see table 1). Immediately the ratio $\mathrm{N} / \mathrm{PO}_{4}$ lowered and remained constant and the new formed leaves showed no deficiencysymptoms any longer. The results of the analyses of series I are irregular when considering the $\mathrm{N} / \mathrm{PO}_{4}$-ratio because of the inadequate supply of phosphate.

The increasing or decreasing ratios at the end of the growing period point to the unequal mobilities of the elements in the plant. It seems that phosphate and nitrogen are more mobile than potassium, which can be ascertained by the comparison of green and dead leaves (see table 3). From these data can be concluded that the mobilities of $\mathrm{N}, \mathrm{P}$ and $\mathrm{K}$ can be arranged in the order : $\mathrm{PO}_{4}>\mathrm{N}>\mathrm{K}$.

The means of the ratios (computed without the abnormal values due to phosphate deficiency) are given in table 4 with the yields of paddy and straw, while the relation between leaf $\mathrm{N} / \mathrm{K}$-ratio and yield in paddy and straw is shown in fig. 1 . This figure shows a close nelationship between yield and leaf composition.

From these observations can be concluded that the result of foliar analysis of rice in an early stage of development is a good indicator of its performance. A crop age of about 30 days will be suitable for the analysis. The choice of this age has furthermore the following advantages: 1) The plant is relatively small and consists predominantly of green leaves; a choice of which leaf has to be analysed is not necessary and the whole plant can be taken. 2) The tillers, formed in this period, have the greatest chance to bear paddy (Go BAN Hong, 1957). 3) The greatest absorption of $\mathrm{N}, \mathrm{P}$, and $\mathrm{K}$ has already started, 


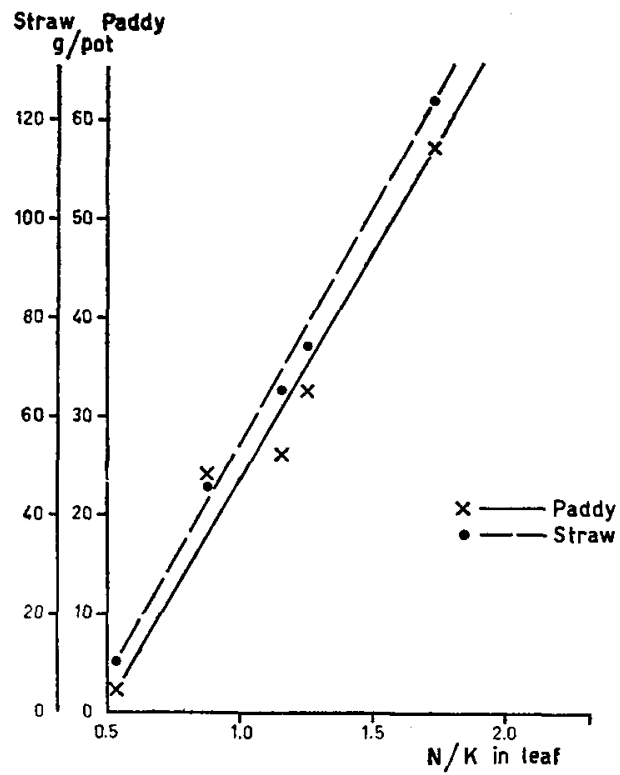

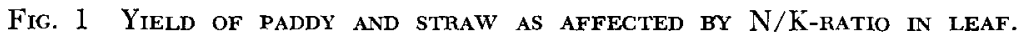

so that differences in fertility level will then be very pronounced (Go BAv HoNG, 1957). 4) Errors, made in the fertiliser-supply of the crop can be corrected for in the same growing season (see table 3).

The results with sugar cane are given in table 5. It appears that the ratios in the whole plant are fairly constant ${ }^{4}$ ), except those at the end of the third month. This was caused by the shortage of especially $\mathbf{N}$ and $\mathrm{P}$. The composition, when considering the $\mathrm{K} / \mathrm{PO}_{4}$-ratio, at the end of the 4 th month is more or less equal to that at the end of the second month as a consequence of the just started supply of additional nutrients. This probably means that the uptake of $\mathrm{K}$ and $\mathrm{P}$ by the plant and their mobilities in the plant are more or less equal. The $\mathrm{N} / \mathrm{PO}_{4}$ - and $\mathrm{N} / \mathrm{K}$-ratios increase with age in the stems, suggesting that $\mathrm{N}$ is more mobile than $\mathrm{P}$ and $\mathrm{K}$; the differences in leaf- and stemcomposition points in the same direction. This leads to the following order of decreasing mobilities : $\mathrm{N}>\mathrm{PO}_{4} \geqslant \mathrm{~K}$.

Because the composition of the whole cane plant (stems and leaves) show the best constancy, it is advisable to analyse the plant as a whole. This, however, is only possible in an early developmental stage because of the voluminosity of the plant. There is no much objection against this, as is indicated above. An age of e.g. two or three months will be suitable.

This conclusion does not mean, that the analysis of the third top leaf with the dewlap, which is usually sampled, is inadequate. The possibility of an early analysis, however, has the same advantages as summed up in the example of lowland rice.

The relation between rendement ${ }^{5}$ ) and the ratios was already reported in an earlier publication (VAN SCHUYLENBORGH and SARJadr, 1958). Additional results

\footnotetext{
4) Some analyses of Borden (1944) and of Schroo and SChMmT (1954) point to the same constancy.

5) Percentage sugar of millable cane.
} 


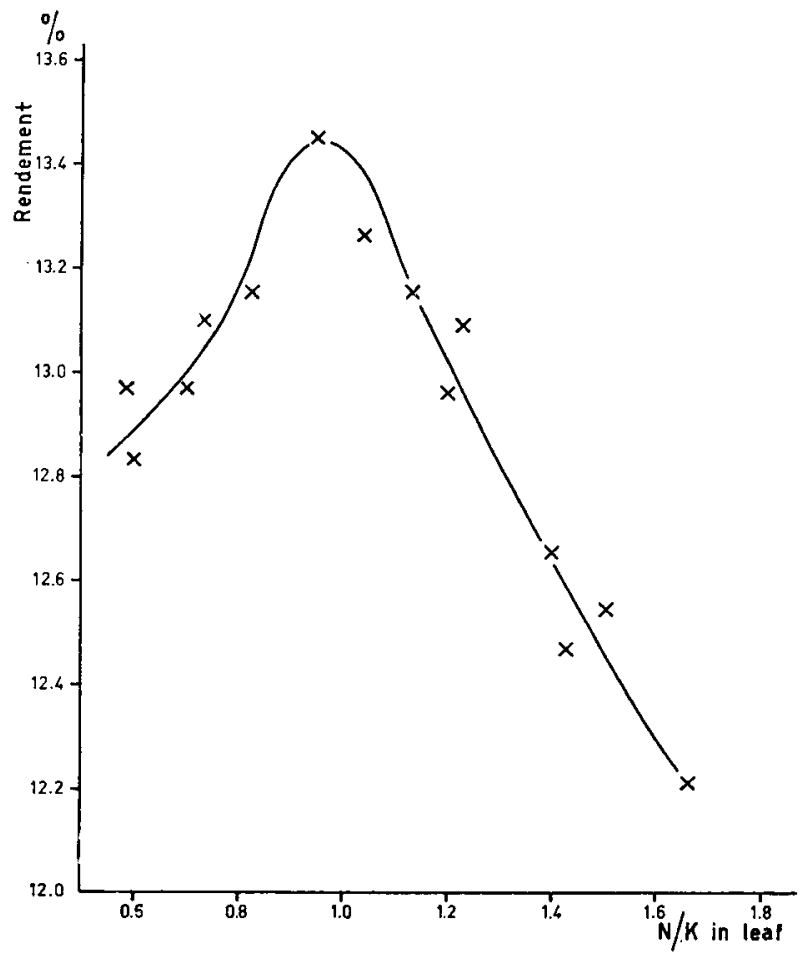

Fig. 2 EFfect of N/K-ratio on RENDEMEnt.

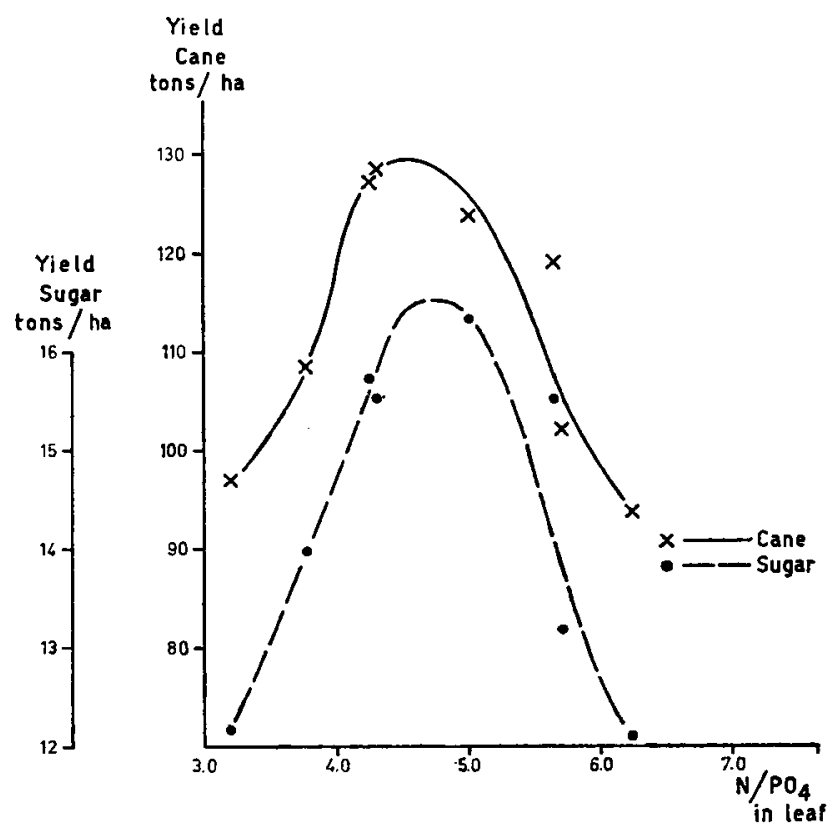

Fig. 3 EFFECT OF N/PO 4 -RATIO ON YIELd OF CANE AND SUGAR. 
from the same experimental fields lead to the relations shown in figures 2 and 3. It is evident that quality as well as quantity is closely related to leaf composition. By comparing the data given by these curves with the cane composition in this paper, it can be seen that the composition of the latter is far from optimal; still its composition is constant, which points to the value of foliar analysis.

It is evident, that foliar composition can be used for annuals as an indicator of their performance, if the distribution of the elements in the plant is known as dependent on age and if the supply with nutrients is continuous. It can be used as a basis of fertilising advices only if the reaction of the plants with different, exactly determinable, fertility levels of the soil is known. It will than be possible to correct an inadequate fertility level in the very same growing season.

\section{ACKNOWLEDGEMENT}

The authors wish to thank Dr. H. Broeshant for valuable critisism.

\section{REFERENCES}

Batley, E. M. and P. J. Anderson : Conn. Expt. Sta., Tobacco Substation, Report 1929. Beauchamp, C. E. and F. Lazo: Proc. Asoc. Techn. Azuc. Cuba 12 (1938) 34.

Borden, R. J. : Hawaii. Plant. Rec. 48 (1944) 43.

Broeshart, H.: The application of foliar analysis in oil palm cultivation. Thesis Wageningen, 1955 .

Chemistry Department, Experiment Station, H.S.P.A. : Hawaii. Plant. Rec. 48 (1944) 213.

Go Ban Hong: On the mineral nutrition of lowland rice (Oryza sativa L.). Thesis Bogor, 1957.

Goodall, W. and F. G. Gregory : Imp. Bur. Hort. Plant. Crops, Techn. comm. No. 17, 1947.

Hoogland, D. R. and D. I. Annon: Agric. Exp. Sta. Calif., Circ. 347, 1938.

MmDelburg, H. A.: Meded. Proefstat. Vorstenl. Tabak, No. 75, 1932; Id. No. 84, 1937. Peach, K. and M. V. Tracey : Modern methods of Plant Analysis. Vol. I. Berlin, 1956.

Scheel, K. C. : Z. Anal. Chem. 105 (1936) 256.

Schroo, H. and N. O. Schmmt : Trop. Agric. 31 (1954) 161.

SchuYlendorgh, J. van and R. M. SARJAdi : Neth. J. Agric. Sci. 6 (1958) 256.

WALKLEY, A.: Austr. J. Exp. Biol. and Med. Sci. 20 (1942) 139. 
Table 1 Amounts and forms of nutritional elements supplied in the rice experiments.

\begin{tabular}{|c|c|c|c|}
\hline \multirow{2}{*}{$\begin{array}{c}\text { Element } \\
\text { or } \\
\text { radical }\end{array}$} & \multirow{2}{*}{$\begin{array}{c}\text { 1st season: June-Nov. '56 } \\
\text { series I }\end{array}$} & \multicolumn{2}{|c|}{ 2nd season: Nov. 1956-May 1957} \\
\hline & & series II & series III \\
\hline $\begin{array}{l}\left.\mathrm{K}^{5}\right) \\
\left.\mathrm{Mg}^{5}\right) \\
\left.\mathrm{Ca}^{5}\right)\end{array}$ & $\begin{array}{l}\left.460 \mathrm{mg} \text { as }\left(\mathrm{NH}_{4}\right)_{2} \mathrm{SO}_{4}{ }^{1}\right) \\
\left.550 \mathrm{mg} \text { as } \mathrm{H}_{3} \mathrm{PO}_{4}{ }^{3}\right) \\
325 \mathrm{mg} \text { as } \mathrm{K}_{2} \mathrm{SO}_{4} \\
25 \mathrm{mg} \text { as } \mathrm{MgSO}_{4} \\
580 \mathrm{mg} \text { as } \mathrm{CaCO}_{3}\end{array}$ & $\begin{array}{l}\left.750 \mathrm{mg} \text { as }\left(\mathrm{NH}_{4}\right)_{2} \mathrm{SO}_{4}{ }^{2}\right) \\
\left.\left.550 \mathrm{mg} \text { as } \mathrm{Ca}_{3}\left(\mathrm{PO}_{4}\right)_{2}\right)^{4}\right) \\
\left.265 \mathrm{mg} \text { as } \mathrm{H}_{3} \mathrm{PO}_{4}\right) \\
325 \mathrm{mg} \text { as } \mathrm{K}_{2} \mathrm{SO}_{4} \\
125 \mathrm{mg} \text { as } \mathrm{MgSO}_{4} \\
925 \mathrm{mg} \text { as } \mathrm{CaCO}_{3}\end{array}$ & $\begin{array}{l}\left.750 \mathrm{mg} \text { as } \mathrm{NH}_{4} \mathrm{NO}_{3}{ }^{2}\right) \\
\left.\left.550 \mathrm{mg} \text { as } \mathrm{Ca}_{3}\left(\mathrm{PO}_{4}\right)_{2}\right){ }^{4}\right) \\
\left.265 \mathrm{mg} \text { as } \mathrm{H}_{3} \mathrm{PO}_{4}\right) \\
325 \mathrm{mg} \text { as } \mathrm{K}_{2} \mathrm{SO}_{4} \\
125 \mathrm{mg} \text { as } \mathrm{MgSO}_{4} \\
925 \mathrm{mg} \text { as } \mathrm{CaCO}_{3}\end{array}$ \\
\hline
\end{tabular}

1) Supplied in 6 equal amounts at $4,24,53,69,76$, and 86 days age.

2) Provided in 10 equal amounts at $2,9,22,43,49,55,60,67$, and 84 (double amount) days age.

3) Applied in 2 equal amounts at 10 and 91 days age.

4) $\mathrm{Ca}_{3}\left(\mathrm{PO}_{4}\right)_{2}$ as basic dressing and $\mathrm{H}_{3} \mathrm{PO}_{4}$ after 49 days growth.

5) As basic dressing.

In series II and III $5 \mathrm{ml}$ solution of micro-elements were supplied to each pot at one day before transplanting. The composition of the solution was : $1.5 \mathrm{mmol}^{2} \mathrm{MnSO}_{4} ; 0.25$ $\mathrm{mmol} \mathrm{CuSO}_{4} ; 0.25 \mathrm{mmol} \mathrm{ZnSO}_{4} ; 10 \mathrm{mmol} \mathrm{H} \mathrm{H}_{3} \mathrm{BO}_{3} ; 0.25 \mathrm{mmol}\left(\mathrm{NH}_{4}\right)_{2} \mathrm{MoO}_{4}$.

Table 2 Composition and concentration of the nutrient solution (series IV).

\begin{tabular}{l|c|l|c}
\hline $\begin{array}{c}\text { Major elements } \\
\text { salt }\end{array}$ & $\begin{array}{c}\text { Concentration } \\
\text { mmol } / 1\end{array}$ & \multicolumn{1}{c}{$\begin{array}{c}\text { Trace elements } \\
\text { salt }\end{array}$} & $\begin{array}{c}\text { Concentration } \\
\text { mmol/l }\end{array}$ \\
\hline $\mathrm{KNO}_{3}$ & 2.50 & $\mathrm{MnSO}_{4}$ & $1.50 \times 10^{-3}$ \\
$\mathrm{Ca}\left(\mathrm{NO}_{3}\right)_{2}$ & 0.50 & $\mathrm{CuSO}_{4}$ & $0.25 \times 10^{-3}$ \\
$\mathrm{KH}_{2} \mathrm{PO}_{4}$ & 0.50 & $\mathrm{ZnSO}_{4}$ & $0.25 \times 10^{-3}$ \\
$\mathrm{MgSO}_{4}$ & 0.25 & $\left(\mathrm{NH}_{4}\right)_{2} \mathrm{MoO}_{4}$ & $0.25 \times 10^{-3}$ \\
& & $\mathrm{H}_{3} \mathrm{BO}_{3}$ & $1.0 \times 10^{-2}$ \\
& & $\mathrm{FeNH}_{4}\left(\mathrm{SO}_{4}\right)_{2}$ & $5.0 \times 10^{-2}$ \\
\hline
\end{tabular}

The pots contained 5 l solution.

Table 3 Element-concentration ratios in green and dead leaves of rice.

\begin{tabular}{|c|c|c|c|c|c|c|c|c|c|c|c|c|c|c|c|c|c|}
\hline \multirow{3}{*}{$\begin{array}{l}\text { Age } \\
\text { (days) }\end{array}$} & \multicolumn{4}{|c|}{ Series I I) } & \multicolumn{4}{|c|}{ Series II } & \multicolumn{4}{|c|}{ Series III } & \multirow{3}{*}{ Age } & \multicolumn{4}{|c|}{ Series IV } \\
\hline & \multicolumn{2}{|c|}{$\mathrm{N} / \mathrm{PO}_{4}$} & \multicolumn{2}{|c|}{$N / K$} & \multicolumn{2}{|c|}{$\mathrm{N} / \mathrm{PO}_{4}$} & \multicolumn{2}{|c|}{$\mathrm{N} / \mathrm{K}$} & \multicolumn{2}{|c|}{$\mathrm{N} / \mathrm{PO}_{4}$} & \multicolumn{2}{|c|}{$\mathrm{N} / \mathrm{K}$} & & \multicolumn{2}{|c|}{$\mathrm{N} / \mathrm{PO}_{4}$} & \multicolumn{2}{|c|}{$\mathrm{N} / \mathrm{K}$} \\
\hline & $\begin{array}{l}8 \\
8 \\
50\end{array}$ & 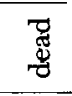 & $\begin{array}{l}\Phi \\
\$ \\
\underbrace{}_{0}\end{array}$ & 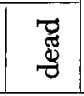 & $\begin{array}{l}\Phi \\
\$ \\
5\end{array}$ & 急 & $\$_{0}$ & $\begin{array}{l}\mathbb{g} \\
\mathbb{E}\end{array}$ & $\begin{array}{l}\frac{5}{8} \\
50\end{array}$ & 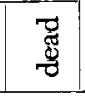 & $\begin{array}{l}8 \\
5\end{array}$ & $\begin{array}{l}\mathbb{\nexists} \\
\Phi\end{array}$ & & $\begin{array}{l}\Phi \\
\Phi \\
\\
\end{array}$ & 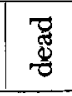 & 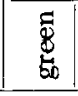 & 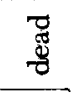 \\
\hline $\begin{array}{c}0 \\
21 \\
42 \\
63 \\
84 \\
95 \\
105 \\
126 \\
\text { harvest }\end{array}$ & $\begin{array}{c}- \\
-\overline{3} \\
9.32 \\
3.98 \\
3.53 \\
- \\
2.08 \\
1.58 \\
1.65\end{array}$ & $\begin{array}{l}- \\
- \\
- \\
- \\
- \\
\overline{-} \\
5.34 \\
5.94 \\
5.32\end{array}$ & $\begin{array}{c}- \\
\overline{-} \\
1.02 \\
0.79 \\
0.80 \\
- \\
0.86 \\
0.51 \\
0.35\end{array}$ & $\begin{array}{c}\overline{-} \\
- \\
- \\
- \\
\overline{-} \\
0.72 \\
0.73 \\
0.67\end{array}$ & $\begin{array}{c}3.49 \\
- \\
16.5 \\
-\overline{9} \\
3.98 \\
\overline{4} \\
\overline{5} \\
5.32\end{array}$ & $\begin{array}{c}\overline{-} \\
\overline{-} \\
9.04 \\
\overline{6} \\
8.60 \\
\overline{0.04}\end{array}$ & $\mid \begin{array}{c}1.03 \\
1 . \overline{50} \\
\overline{1.13} \\
\overline{1.28} \\
\overline{\overline{7}}\end{array}$ & $\begin{array}{c}\overline{-} \\
\overline{-} \\
\overline{-} \\
0.69 \\
\overline{0} \\
0.69 \\
\overline{0.68}\end{array}$ & $\begin{array}{l}3.49 \\
13.9 \\
11.5 \\
3.90 \\
3.11 \\
3.56 \\
3.58 \\
3.52 \\
3.20\end{array}$ & $\begin{array}{c}- \\
\overline{-} \\
8.30 \\
6.95 \\
6.57 \\
7.07 \\
6.66 \\
6.45\end{array}$ & $\begin{array}{l}1.03 \\
1.49 \\
1.17 \\
1.25 \\
1.10 \\
1.21 \\
1.16 \\
0.92 \\
0.64\end{array}$ & $\begin{array}{c}\overline{-} \\
\overline{-} \\
1.06 \\
0.67 \\
0.69 \\
0.70 \\
0.65 \\
0.63\end{array}$ & $\begin{array}{r}30 \\
40 \\
50 \\
64 \\
78 \\
88 \\
100 \\
111 \\
120 \\
134 \\
153\end{array}$ & $\begin{array}{l}4.58 \\
4.03 \\
4.76 \\
4.29 \\
4.08 \\
4.11 \\
3.93 \\
4.36 \\
4.62 \\
5.10 \\
4.10\end{array}$ & $\begin{array}{c}- \\
- \\
- \\
5.62 \\
4.83 \\
5.20 \\
4.52 \\
4.32 \\
4.53 \\
4.70\end{array}$ & $\begin{array}{l}1.95 \\
1.81 \\
1.83 \\
1.62 \\
1.35 \\
1.51 \\
1.60 \\
1.72 \\
1.83 \\
2.03 \\
1.66\end{array}$ & $\begin{array}{l}\overline{-} \\
\overline{-} \\
\overline{1} \\
1.31 \\
1.47 \\
1.37 \\
1.32 \\
1.36 \\
1.27 \\
1.29\end{array}$ \\
\hline check & 2.85 & - & 0.51 & - & & & & & & & & & & & & & \\
\hline
\end{tabular}

1) After the age of 63 days : leaf and stalk. 
Table 4 Element ratio and yield of paddy and straw.

\begin{tabular}{|c|c|c|c|c|}
\hline Series & $\begin{array}{l}\mathrm{N} / \mathrm{PO}_{4} \\
\text { in leaf }\end{array}$ & $\begin{array}{l}N / K \\
\text { in leaf }\end{array}$ & $\begin{array}{l}\text { Paddy } \\
\text { g/pot }\end{array}$ & $\begin{array}{l}\text { Straw } \\
\text { g/pot }\end{array}$ \\
\hline $\begin{array}{l}\text { Check } \ldots \ldots \ldots \ldots \\
\text { Series I } \ldots \ldots \ldots \ldots \\
\text { Series II } \ldots \ldots \ldots \\
\text { Series III } \ldots \ldots \ldots \\
\text { Series IV } \ldots \ldots \ldots\end{array}$ & $\begin{array}{l}2.85 \\
? \\
3.84 \\
3.48 \\
4.38\end{array}$ & $\begin{array}{l}0.51 \\
0.87 \\
1.24 \\
1.15 \\
1.72\end{array}$ & $\begin{aligned} & 3.4 \pm 0.03 \\
& 22.6 \pm 0.5 \pm 0.5 \\
& 30.5 \pm 0.5 \\
& 24.4 \pm 0.8 \\
& 53.8 \pm 4.4\end{aligned}$ & $\begin{array}{r}14.8 \pm 0.4 \\
42.8 \pm 1.3 \\
69.9 \pm 1.1 \\
61.4 \pm 0.9 \\
116.7 \pm 2.4\end{array}$ \\
\hline
\end{tabular}

Table 5 Element-concentration ratios in sugar cane.

\begin{tabular}{|c|c|c|c|c|c|c|c|c|c|}
\hline \multirow[b]{2}{*}{$\begin{array}{c}\text { Age } \\
\text { (months) }\end{array}$} & \multicolumn{3}{|c|}{ Leaves } & \multicolumn{3}{|c|}{ Stems } & \multicolumn{3}{|c|}{ Leaves + stems } \\
\hline & $\frac{4}{z}$ & $\frac{O^{+}}{z}$ & 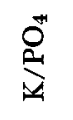 & $\frac{4}{z}$ & $\frac{O^{+}}{\overbrace{}^{+}}$ & $\overbrace{0}^{+1}$ & $\frac{4}{z}$ & $\frac{D^{+}}{z}$ & $\frac{0^{+1}}{8}$ \\
\hline 2 & 1.47 & 7.04 & 4.77 & - & - & - & 1.47 & 7.04 & 4.77 \\
\hline 3 & 1.32 & 9.52 & 9.53 & - & - & - & 1.32 & 9.52 & 9.53 \\
\hline 4 & 2.06 & 9.30 & 4.51 & 0.946 & 7.33 & 7.75 & 1.60 & 8.72 & 5.45 \\
\hline 5 & 1.66 & 9.38 & 5.65 & 1.27 & 11.6 & 8.80 & 1.61 & 10.9 & 6.75 \\
\hline 6 & 1.27 & 7.38 & 5.81 & 1.43 & 11.2 & 7.85 & 1.30 & 8.21 & 6.25 \\
\hline 7 & 1.30 & 8.46 & 6.50 & 2.24 & 15.2 & 6.80 & 1.51 & 9.98 & 6.58 \\
\hline 8 & 1.23 & 8.27 & 6.71 & 2.39 & 17.1 & 7.20 & 1.51 & 10.3 & 6.85 \\
\hline 9 & 1.31 & 8.51 & 6.50 & 2.40 & 19.8 & 8.24 & 1.50 & 9.91 & 6.61 \\
\hline 10 & 1.29 & 8.40 & 6.51 & 2.48 & 21.3 & 8.60 & 1.48 & 9.77 & 6.60 \\
\hline mean & 1.41 & 8.49 & 6.28 & & & & 1.48 & 9.37 & 6.60 \\
\hline
\end{tabular}

